\title{
"Do I Look Fat in This?": The Role of the Mother-Daughter Relationships in Determining Body Image $^{1}$
}

Eboni Baugh ${ }^{2}$

\section{Introduction}

Throughout history, the preparation of food has been part of a woman's traditional domain. Even today, with our diverse families, the mother in a family is typically the primary adult responsible for many household duties related to food and eating, such as:

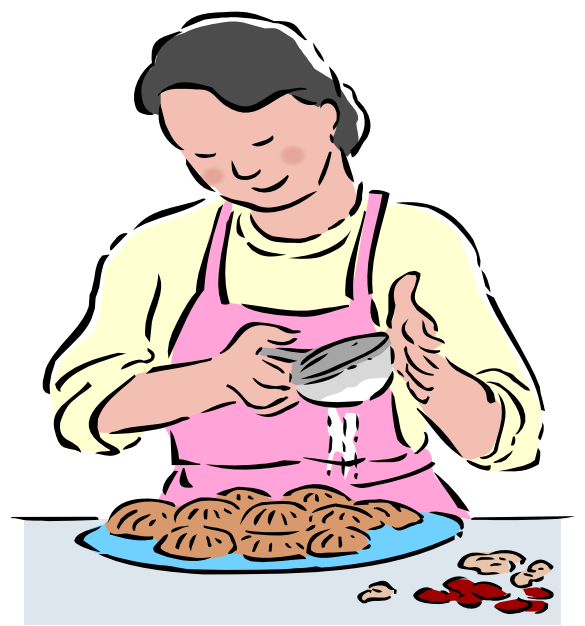

- Grocery shopping

- Meal planning and preparation

- Considering the health effects of food choices

- $\quad$ Reading nutrition labels
- Discussing food options with the family

- Making dietary decisions

In most households, mothers do more than fathers to educate their families about food, nutrition, and dietary intake. They have a major influence on the eating behaviors and attitudes of their children.

Research has highlighted the importance of the relationship between mothers and daughters when it comes to eating, dieting, and body image. Daughters' perceptions of their bodies and subsequent eating and dieting behaviors have been shown to be directly related to the verbal and nonverbal messages they receive from their mothers. Through modeling, teasing, pressure, and even food restriction, mothers make a noticeable impact on their daughters' body image and eating behaviors.

\section{Mothers \& Daughters: A Crucial Relationship}

At early ages, children develop different attitudes about their bodies. Boys and girls receive different messages about their bodies, especially from their parents. Boys tend to strive for more

1. This document is FCS8838, one of a series of the Department of Family, Youth and Community Sciences, Florida Cooperative Extension Service, Institute of Food and Agricultural Sciences, University of Florida. First published April 2007. Please visit the EDIS Web Site at http://edis.ifas.ufl.edu.

2. Eboni Baugh, assistant professor, Department of Family, Youth, and Community Sciences, Florida Cooperative Extension Service, Institute of Food and Agricultural Sciences, University of Florida, Gainesville, 32611.

The Institute of Food and Agricultural Sciences (IFAS) is an Equal Opportunity Institution authorized to provide research, educational information, and other services only to individuals and institutions that function with non-discrimination with respect to race, creed, color, religion, age, disability, sex, sexual orientation, marital status, national origin, political opinions, or affiliations. U.S. Department of Agriculture, Cooperative Extension Service, University of Florida, IFAS, Florida A\&M University Cooperative Extension Program, and Boards of County Commissioners Cooperating. 
“Do I Look Fat in This?”: The Role of Mother-Daughter Relationships in Determining Body Image Page 2

muscle mass by lifting weights excessively and/or consuming muscle growth supplements or drugs. Girls are more likely to adopt weight loss strategies to achieve an "ideal" body size. They may try dieting, excessive exercise, or laxatives and diuretics in order to lose weight.

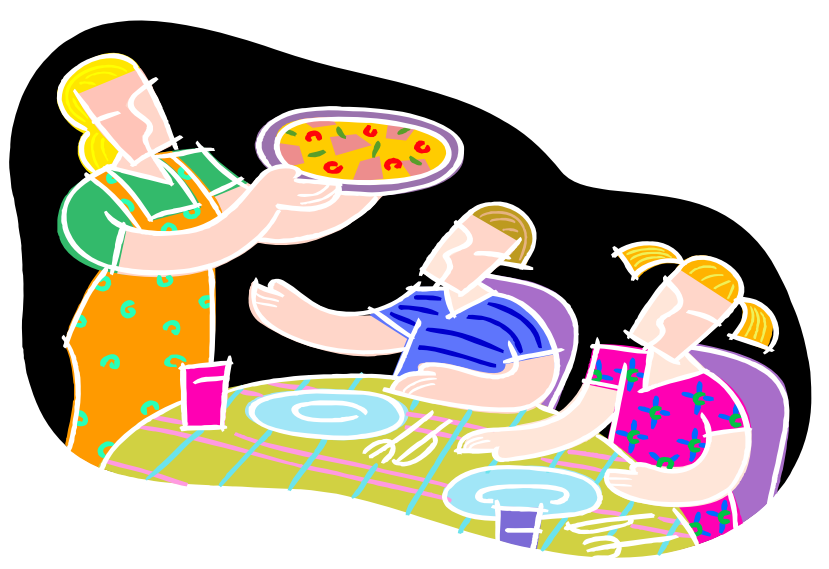

Girls learn at an early age about cultural expectations of the ideal body. Preschool girls report having an aversion to being fat and even reject images of people who are overweight and obese. This anti-fat attitude can lead to dissatisfaction with their own bodies and increase the risk that they will use unhealthy behaviors to achieve the thin ideal. For some, this struggle with body dissatisfaction begins at an early age and continues throughout life, often becoming worse with age.

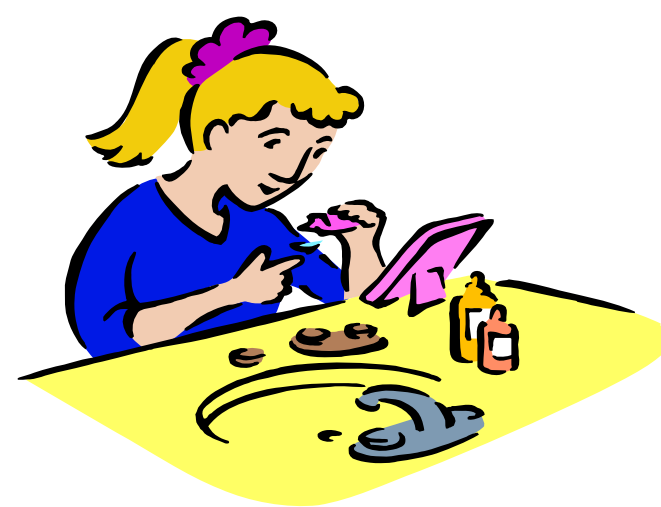

Research reveals that best friends and mothers have the biggest influence on whether or not a girl will use risky behaviors to lose weight. In fact, daughters whose mothers encourage them to lose weight are more likely to be dissatisfied with their bodies (McCabe \& Ricciardelli, 2004). Mothers often promote dieting trying to shield their children from being fat in an anti-fat society.
However, early dieting can lead to a lifelong battle with diet and body image and can increase a child's risk for becoming obese.

A mother's opinion of her own body can also influence her daughter's access to healthy diet in the home. Mothers who are more concerned with their own bodies are more likely to restrict their child's eating, even at early ages. Even mothers who fall within healthy weight ranges or body mass index (BMI) ranges often report a desire to be thinner. These mothers also want their daughters to be thin. When given drawings of children of various body sizes and shapes, most mothers indicated a preference for their child to be closer in size to a thinner, malnourished figure than a heavier, obese figure.

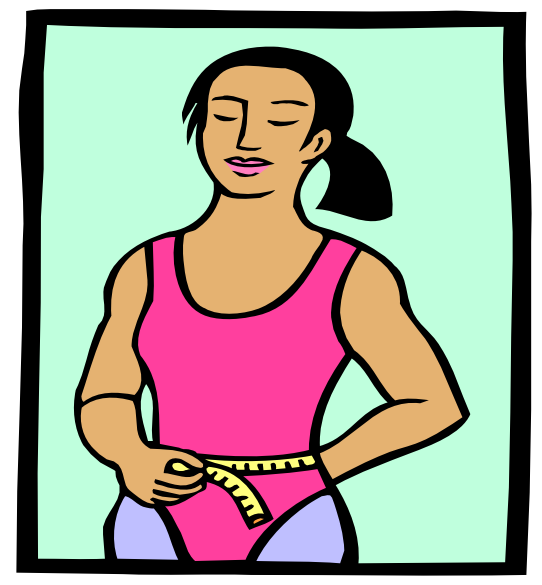

\section{Implications for Mothers, Daughters, and their Families}

It is clear that mothers play an important role in the development of body image in their daughters. Unfortunately, mothers' attitudes often contribute to the development of negative body image and encourage poor eating habits. Family relationships, particularly the mother-child relationship, are crucial to the development of self in children, especially girls. Therefore, we must pay close attention to the messages mothers send their daughters about body image and eating. Mothers must be aware of how their own attitudes and comments affect their daughters. Mothers can help themselves and their daughters develop a more positive body image and begin to reduce risky eating and dieting behaviors. 
“Do I Look Fat in This?”: The Role of Mother-Daughter Relationships in Determining Body Image Page 3

Mothers can begin by asking themselves the following questions:

- How do I feel about my own body?

- Do I make negative comments about my body or the bodies of other women?

- Am I often on a diet, over-exercising, or obsessing about my weight?

- Do I hide my body from my family and friends?

- Am I critical about my child's body?

- Do I make negative comments about my child's weight or eating habits?

- Have I ever restricted my child's food intake for fear that she would get fat?

- Have I focused more attention on my daughter's) weight than my son's?

The internalization of negative messages about their bodies creates the biggest risk for developing eating disorders and engaging in risky weight loss behaviors in girls. Girls are more sensitive than boys to this information and to messages and nonverbal cues they receive from others about their bodies.

Mothers and friends are more significant influences on girls' body image than messages from the mass media. Knowledge of this important relationship is vital when dealing with issues about our bodies. Mothers and daughters have numerous resources readily available to them to help create and build a positive body image.

\section{Resources}

\section{Books:}

Pierson, S., \& Cohen, P. (2003). You have to say I'm pretty, you're my mother: How to help your daughter learn to love her body and herself. New York: Simon \& Schuster.

Johnson, C. A. (2001). Self-esteem comes in all sizes: How to be happy and healthy at your natural weight. Carlsbad, CA: Gurze Books.

Richardson, B. L., \& Rehr, E. (2001). 101 ways to help your daughter love her body. New York: Harper Collins.

\section{On the Web:}

Women's Heath:

http://womenshealth.gov/BodyImage/

http://www.bodyimagehealth.org/

Nemours Foundation:

http://www.kidshealth.org/teen/your_mind/body_ image/body_image.html

National Eating Disorders Association - Body

Image:

http://www.edap.org/p.asp?WebPage_ID=286\&

Profile_ID=41157

\section{References}

Forbes, G. B., Adams-Curtis, L., Jobe, R. L., White, K. B., Revak, J., Zivcic-Becirevic, I., \& Pokrajac-Bulian, A. (2005). Body dissatisfaction in college women and their mothers: cohort effects, developmental effects, and the influence of body size, sexism, and the thin body ideal. Sex Roles: A Journal of Research, 53, 281-263.

Jaffe, K., \& Worobey, J. (2006). Mothers' attitude towards fat, weight, and dieting in themselves and their children. Body Image, 3, 113-120.

McCabe, M. P., \& Ricciardelli, L.A. (2006). A prospective study of pressures from parents, peers, and media on extreme weight change behaviors among adolescent boys and girls. Behaviour Research and Therapy, 43, 653-668.

Musher-Eizenman, D. R., Holub, S. C., EdwardsLeeper, L., Persson, A. V., \& Goldstein, S. E. (2003). The narrow range of acceptable body types of preschoolers and their mothers. Journal of Applied Development Psychology, 25, 541 543. 